\title{
VIEJOS MITOS PARA «NUEVOS» TIEMPOS: EL MITO DEL MINOTAURO COMO REIVINDICACIÓN DE LA ALTERIDAD Y ESPEJO ESCÉPTICO FRENTE A LOS GRANDES RELATOS
}

\author{
ALEXANDRA DINU \\ Universitat de Barcelona \\ alexandradinu@ub.edu \\ ORCID: 0000-0001-9949-4319
}

\section{RESUMEN}

El objetivo de este trabajo es mostrar y analizar las variaciones que sufre el mito del Minotauro en las obras de dos escritores familiarizados con el mundo clásico como Julio Cortázar en Los Reyes y Jorge Luis Borges en el cuento «La casa de Asterión». Se indaga en las posibles razones que los animaría a volver sobre la tradición clásica, especialmente griega, y a actualizar el mito del Minotauro a finales de la década de los años cuarenta en una reescritura intertextual propia de la posmodernidad que arranca de distintos hipotextos; entre ellos, la Biblioteca de Apolodoro, la Descripción de Grecia de Pausanias, Hipólito de Eurípides, o Plutarco en los capítulos dedicados al Minotauro en la Vida de Teseo de Vidas paralelas. Para ello, se parte de la hipótesis de que ambos escritores miraron y leyeron con escepticismo el mitema en sus distintas configuraciones, reforzando la historia con aspectos imprevisibles y fantásticos y combatiendo la fe en la razón griega.

PALABRAS CLAVE: Minotauro, identidad, experimentación, reescritura, posmodernidad.

OLD MYTHS FOR “NEW” TIMES: THE MYTH OF THE MINOTAUR AS A VINDICATION
OF THE OTHERNESS AND AS A SKEPTICAL MIRROR AGAINST THE GREAT STORIES

\section{ABSTRACT}

The objective of this work is to show and analyze the variations that the myth of the Minotaur undergoes in the works of two writers familiar with the classical world, such as Julio Cortázar in Los Reyes and Jorge Luis Borges in his tale "La casa de Asterión". In this study, we investigate the possible reasons that would encourage them to return to the classical tradition, especially the Greek one, and to update the myth of the Minotaur at the end of the 1940s in an intertextual rewriting. This is a typical trait of postmodernity that starts from different hypotexts; among them, Apollodorus' Library, Pausanias' Description of Greece, Euripides' Hippolytus and Plutarch in his chapter about Theseus in Parallel Lives. For this, this work is based on the hypothesis that both writers looked and read with skepticism the mytheme in its different configurations, reinforcing the story with unpredictable and fantastic aspects, and fighting the faith in the Greek reason.

KEYWORDS: Minotaur, identity, experimentation, rewriting, postmodernity. 


\section{INTRODUCCIÓN}

En 1949, el mito del Minotauro cobra especial relevancia en la literatura argentina. Jorge Luis Borges escribe para el diario Los anales de Buenos Aires «La casa de Asterión», un cuento en el que ofrece un minotauro redimido con el que consigue la implicación emocional del lector. En el mismo año, Julio Cortázar publica Los reyes, una obra clasificada de poema con dramático en la que el auténtico héroe es el minotauro, porque encarna ya no valores épicos y guerreros como los de Teseo, sino lírico-filosóficos. Así, este trabajo se propone como un recorrido por las razones y modos de la reformulación de este mito en las obras mencionadas, desde las modificaciones formales realizadas por Borges y Cortázar hasta las distintas metamorfosis genéricas caracterizadas por la inversión del héroe de la historia. Abordaremos desde el ser incapaz de conocer y conocerse de Borges hasta la defensa del ser diferente y transgresor de las reglas del establishment de Cortázar.

Sobre los cambios temáticos y estructurales, «La casa de Asterión» (1947) no plantea ningún problema respecto a su forma o género, pues es un cuento breve incluido en El Aleph (1949), que reflexiona sobre el tema de la soledad y que, además, se inicia con una cita libre procedente del compendio mitográfico de la Biblioteca de Apolodoro (III 1, 11), en la que ya descubrimos el nombre que recibe el personaje: «Y la reina dio a luz un hijo que se llamó Asterión» (Borges 1984: 69). Se trata de la primera señal del vínculo entre la fuente clásica y el texto borgeano, esto es, del proceso intertextual, según la concepción restrictiva de Genette (1989: 10) respecto de otros estudiosos como «una relación de copresencia entre dos o más textos, es decir, eidéticamente y frecuentemente, como la presencia efectiva de un texto en otro».

En cambio, Los Reyes parece una obra de teatro formada por cinco escenas, aunque en realidad es un poema dramático, como lo ha llamado su autor, un poema dialogado que combina versos heptasílabos, endecasílabos y alejandrinos. Ateniéndonos al capítulo VI de la Poética de Aristóteles, la obra debería considerarse una tragedia, por la presencia de personajes nobles, el fin trágico y la incorporación especial de mitos clásicos. No obstante, carece de elementos propios de una obra de teatro, como acotaciones (apenas contiene didascalias para indicar el paso de una escena a otra) o alguna referencia a una posible representación. Las únicas indicaciones de su naturaleza dramática son los diálogos y los monólogos de los personajes. Por tanto, a partir de la transgresión de género, sin límites claros entre poesía y teatro - lo cual contraviene las «reglas» de la obra de Aristóteles - se pueden interpretar los cambios formales como una férrea reivindicación de la experimentación literaria que el propio autor pone de manifiesto en declaraciones como la siguiente:

Si hay alguna cosa que defiendo por mí mismo, por la escritura, por la literatura, por todos los escritores y todos los lectores, es la soberana libertad de un escritor de escribir lo que su conciencia y su dignidad personal lo llevan a escribir. (Cortázar 2015: 33) 


\section{LAS VARIACIONES POSMODERNAS SOBRE EL MITO CLÁSICO Y SUS EFECTOS ESCÉPTICOS Y DESMITIFICADORES}

La historia propiamente dicha presenta, en las nuevas reescrituras, un inicio que cabría denominar in medias res, ya que tanto Borges como Cortázar eliminan la secuencia temporal de los orígenes y el nacimiento del Minotauro para retomar el mito a partir de su encierro en el laberinto y su posterior muerte a manos de Teseo. De esta manera, nos encaminamos hacia una transgresión del fondo, del contenido, que afecta al «argumento central» de la historia y a los motivos secundarios, pues ambos autores conceden absoluto protagonismo a la figura del Minotauro, y no a la del héroe habitual, Teseo. Esta forma de aproximación a un motivo clásico basado en omisiones, alusiones, citas, plagios, traducciones y nuevas incorporaciones rompe con la lógica y la estructura de los textos que leyeron los autores objeto de nuestro análisis con la «finalidad [de] poner en crisis el carácter sacro, clausurado y original de un texto» (Scavino y Buzón 20081).

Así, Cortázar prescinde de los personajes de Pasífae, Dédalo, Androgeo, Egeo o de los dioses Poseidón y Zeus; Borges va más allá y borra los rastros del hecho contra natura de Pasífae (a diferencia de Cortázar) o la traición de Ariadna, y convierte a Asterión no solo en el personaje principal, sino también en el narrador del relato en forma de monólogo hasta la última línea. En el cuento borgeano, con la irrupción de Teseo y Ariadna, se cambia de perspectiva y de voz narrativa, y se revela de forma clara el proceso de intertextualidad presente. De este modo, el texto dialoga con la fuente clásica a modo de espejo, y asume y transforma parte del texto de Apolodoro para intervenir y contravenir la historia primigenia. Ello es posible a través de un proceso de elusión presente en todo el cuento con el que se esconde la identidad del protagonista hasta la última línea, en la que se menciona la mansedumbre del minotauro, su total rendición bajo el acero de Teseo.

En el drama de Cortázar, el tríptico dibujado enmarca a Minos, Teseo y al Minotauro como protagonistas absolutos de la acción y del final fatal de este último. Minos, en la versión de Cortázar, continúa siendo un rey carcomido por la codicia que vive compungido, desgraciado y con miedo a ser destronado por el ser que lo avergüenza y atormenta hasta en sus pesadillas por más que lo haya tratado de olvidar, ocultar y reducir en una prisión. El supuesto antihéroe, el Minotauro, por el contrario, es un ser tierno, dócil, incomparablemente bello, pacífico, afligido por su doble naturaleza humana y animal, el «señor de los juegos» y «amo de los ritos» (Cortázar 1970: 73), es decir, un auténtico rey que despierta la sensibilidad por las artes y crea una forma de gobierno utópica e ideal en una cárcel-laberinto que se revela casa, en la que sus «víctimas», su corte feliz y agradecida, son los amigos que no tenía el Asterión de Borges. Esta caracterización implica una fundamental reconfiguración de la noción de

\footnotetext{
${ }^{1}$ La versión consultada para la elaboración de este estudio carece de numeración.
} 
heroicidad, dado que a Teseo se le atribuyen asesinatos anteriores motivados por una enfermiza y obsesiva sed de poder. Además, la relación que Cortázar propone entre la figura del minotauro y la música no es casual, ya que esta «lleva, pues, al límite del sistema del signo» (Kristeva 1988: 280), que es una propuesta constante en la obra del autor argentino. Con ello, crea una radical división de Teseo, representante de un territorio lógico y racional, frente a un minotauro que pretende dominar a través de lo lúdico - motivo fundamental en la poética cortazariana - , de su canto, de la poesía, en un plano ontológico. De este modo, convierte al monstruo caracterizado por su grandeza e hibridez humano-animal en un «monstruo» destacado por lo maravilloso, esto es, por lo artístico e inocente. Así se explica que el Minotauro anime al citarista a seguir cantando y, a su compañera, a continuar danzando, pues en su obra de carácter crítico, ensayístico y teórico, concretamente en el texto titulado Para una poética, Cortázar (2017: 387-388) «glosa» las implicaciones identificativas del canto y del ser.

El Minotauro, tanto en la versión cortazariana como en la borgeana, invierte las características que se le atribuían por indefensión, desamparo y fragilidad. Estamos, así, ante una uariatio tanto de los rasgos de este personaje como del acto fundamental desencadenante del viaje del héroe, esto es, del sacrificio (esa tauromaquia sagrada que es el asesinato del Minotauro, propia de las religiones prehelénicas), el entorno donde se desarrolla (el laberinto) y el momento, desprovistos de su carácter de ritual sagrado (Eliade 1992: 17). La intención del autor se puede resumir en un deseo de derribar los valores militares. Así, las reminiscencias de la historia minoica, materializadas en forma de referencias al asunto del Laberinto, el tributo ateniense a Cnossos o la unificación del Ática por Teseo, pueden responder a una crítica a la figura de los «héroes» nacionales argentinos, un hecho habitual en la obra de Cortázar, si se valora el desencanto político que motivó, entre otros asuntos, su marcha de Argentina.

La demonización de Teseo y la dotación de atributos distantes de los del caudillo (de la obra de Eurípides) parecen indicar el rechazo de Cortázar al gobierno peronista: podría ser su respuesta a los grandes relatos sobre la nación argentina. Y es que, en los años 30 y 40, Cortázar no era el escritor comprometido que sería a raíz de los movimientos de liberación cubana y nicaragüense, ni mucho menos era aún consciente de su «latinoamericanidad», sino que era un escritor de maneras burguesas, partidario del socialismo y reacio al populismo peronista que afloró desde el año 1945, cuatro años antes de la publicación de las obras que analizamos. En consecuencia, el Teseo de Cortázar ya no actúa como héroe de su pueblo, sino como sujeto individualista que aspira a acallar la fama del rival que le hace competencia, porque Teseo no puede «volver a Atenas sin que lo sobrevuele la noticia de otro monstruo vencido» (Cortázar 1970: 41).

En el mundo de Cortázar, el mito se convierte en una forma de pensamiento filosófico; es un arma de carácter emocional, en el sentido que le da Aristóteles a la tragedia, en tanto que causante de una catarsis de temor y, especialmente, de piedad (también en el cuento de Borges). Esta «arma» se usa para combatir la 
lógica, la razón, la convención y la costumbre entendida como enemiga de la imaginación, la intuición y la espontaneidad; el mito, pues, es un instrumento propicio dada su proximidad con el mundo onírico y del inconsciente.

La promoción de los atenienses es ahora exaltación del Minotauro. Y es que tanto el «mito» de Cortázar como el de Borges aspiran al cumplimiento de un deseo personal: una mejor forma de gobierno en la que tenga cabida la diferencia y las excepciones a la convención, a la razón y al orden, en el caso de Cortázar; o, en el caso de Borges, la expresión de la idea de que en todo hombre hay un otro o la obsesión por el tema del laberinto como construcción metafísica, psicológica $\mathrm{y}$ existencial, que en última instancia refleja la condición del hombre moderno (y posmoderno) y su radical soledad.

El segundo eje de variación más importante en Cortázar afecta a Ariadna - ahora Ariana - , ya que esta siente por el cabeza de toro la misma pasión irrefrenable que su madre sentía por el toro de mar no sacrificado. En la tercera escena, se produce la transgresión fundamental de la historia: se introduce el leitmotiv del incesto $-\mathrm{o}$, mejor dicho, del deseo de incesto - frecuente en la mitología griega, pero también en otras obras del argentino. Es este aspecto el que convierte al Minotauro en un monstruo, sus orígenes, el «pecado» que cometió su madre, ya que, si nos atenemos a la tipología establecida por Kappler (2004: 138-150), nuestro personaje no posee defectos físicos como ausencia de alguna parte del cuerpo o algún tipo de exceso o desproporción. Se trata de un ser híbrido, y ese es su defecto, pues también según Kappler (2004: 171) «los seres humanos con cabeza de animal aparecen en la imaginación mítica desde las más antiguas civilizaciones y llegan hasta nosotros».

\section{EL YO, EL OTRO: LOS ESPEJOS DE LA ALTERIDAD Y LOS CONFLICTOS DE LA IDENTIDAD}

En cuanto a la alteridad, para Cortázar es Teseo el ser incapaz de conocer al otro, es decir, al Minotauro, cegado por su soberbia y por el deseo de poder en tanto que lo ve en términos de monstruo y no acepta lo distinto, la parte animal, al toro, y lamenta no poder salvar «el resto», su «cuerpo todavía adolescente» (Cortázar 1970: 60). Podríamos considerar a Teseo, por tanto, como un sujeto posmoderno en tanto que sufre una crisis de identidad al ir al encuentro del otro, para reafirmarse como héroe dominante y universal, al enfrentar la lógica de la razón sobre la que sostiene su superioridad sobre el monstruo y finalmente descubrirse otro en la figura del Minotauro. Por otro lado, este también se siente ser un «otro» diferente en la mirada ajena de Teseo una vez liberado de su casa, el laberinto, porque ahí, dado que aceptaba su propia condición, era completamente libre: «era especie e individuo, cesaba mi monstruosa discrepancia» (Cortázar 1970: 61). Debido a los desafíos de Teseo con el único fin de enaltecer su propia vanidad y rebajar al monstruo a nada más que miedo, el Minotauro vuelve, no obstante, a la «doble condición animal» (Ibidem), al ser mirado. 
La concepción de lo monstruoso en la cultura y más concretamente en la literatura a partir de la definición de Santiesteban Oliva en su Tratado de monstruos (2003: 97), que resume sus principales características, será la que nos encontramos en el Minotauro: forma híbrida, reducida a bestia por su cabeza animal, propias del mito original aquí transgredido. Así, los rasgos que lo conforman (carácter efímero, muerte predestinada en manos de un «héroe», figura animal que infunde horror, ser moralmente malo, etc.) lo hacen propicio para el interés de un escritor como Borges, cuyos temas esenciales son la inmortalidad y, por tanto, su contrario (la figura del doble). En este recopilatorio queda implícita nuevamente la habitual práctica de la inter/transtextualidad en su obra, que desempeña dos funciones principales: cuestionar la autoría y lanzar a los lectores ante el problema de «la muerte del autor», tal como se entiende a partir de Barthes (1994: 65-72). El Minotauro cortazariano es pieza imprescindible en el juego de espejos de la fama en el que Teseo se quiere proyectar, pues su intento no es otro que el de intentar acabar con la representación que el Minotauro tiene de sí mismo, esto es, con la obscenidad de lo oculto, lo secreto, lo reprimido, lo oscuro, elementos siempre gratos para Cortázar y habituales en su obra. Teseo no lo mira con los ojos del que va a rendir al mito, como le increpa el Minotauro, sino con los ojos de alguien que busca poner fin a la imagen, a la representación. Bajo esta interpretación es el Minotauro quien rinde realmente a Teseo por el temor de este a la obscenidad comunicacional y cercana de la cabeza de toro: entre ambos, se impone la saturación superficial de Teseo, que no está dispuesto a la solicitud incesante del otro ni permite ningún espacio intersticial de comunicación, que no tolera la extraversión forzada de su interioridad que le tantea el Minotauro en su diálogo.

El desconocimiento es el motor de las acciones de Teseo en el drama de Cortázar; por ello, se dirige al Minotauro con unas palabras tan elocuentes e indicativas de su forma de pensar e intenciones como las siguientes: «No sé nada de ti: eso da fuerza a mi mano» (1970: 64). Aunque el Minotauro le cuestiona su capacidad de matar sin imaginar ni conocer al otro (con el consiguiente bloqueo comunicativo), Teseo se mueve no por los discursos, sino por la acción. De este modo, siempre rechaza el diálogo (como Asterión rechaza el sistema cultural escritocéntrico y logocéntrico como forma de la felicidad), la manera de conocer al otro, y ordena silencio, «harto de palabras, perras sedientas» (Cortázar 1970: 68) porque «los héroes odian las palabras» (Ibidem). Así se explican la distancia e inconsciencia desde las que deshumaniza al otro y le posibilitan la violencia cuando dice: «Mataré a ese demonio, arrastraré su cuerpo vestido de polvo por las calles de Cnossos» (1970: 39). Incomunicación y soledad tienen un efecto similar sobre el Minotauro de Borges, porque este no acepta su monstruosidad, sino que se cree único por su nacimiento y orígenes reales. Su incapacidad para comprender el mundo exterior ligada a la desconfianza de las palabras (otro laberinto) y la escritura (como posible refugio) niegan cualquier posibilidad de relación, ya que ni Teseo conoce al Minotauro de atributos infantiles de Borges 
ni el Minotauro percibe su propia ferocidad. En suma, el minotauro es símbolo de una identidad cuestionada, del escepticismo y relativismo del que hacen gala los autores.

En «La casa de Asterión» y Los reyes representa la caída del hombre moderno, la quiebra de las seguridades. Por ello en la obra de Borges el Minotauro es un ser solitario que despierta compasión o conmiseración en su configuración patética; así pues, desconfía de cualquier sistema, de todo intento de conocimiento y transmisión del pensamiento, del mundo cultural, del laberinto mismo que constituyen la escritura y el lenguaje. No podía ser de otro modo si, partiendo de los principios básicos de lingüística y comunicación descritos por Kristeva (1988: 9), consideramos que «el mensaje destinado al otro está, en cierto sentido, destinado en primer lugar al propio hablante: de lo que deducimos que hablar es hablarse».

Resulta revelador que Borges haya optado por la focalización del pensamiento del minotauro, porque este desplazamiento del foco de atención indica la búsqueda no solo de un otro o un doble, sino también el anhelo de sus palabras y pensamientos, del diálogo. La identidad se construye en relación con la exterioridad; por ello, Asterión imagina posibles amigos e incluso sale a ese otro laberinto inmenso y manifiesta que el doble habita en el propio «yo», en clara búsqueda de un otro que al no ser encontrado propicia la revelación del «yo» como alteridad. El diálogo no surge tanto como una invitación, sino como una necesidad de la identidad en un mundo de otros, pues, como indica Alvarado (2019: 17), en la obra de Borges

el Minotauro se hace humano a través de la palabra, se muestra consciente de su apariencia, [...] se muestra consciente de su identidad, y se desvela, además de su carácter reflexivo, su sensibilidad. (Alvarado 2019: 17)

En suma, ambos autores demuestran que la identidad como sinónimo de unicidad (como reivindica el minotauro en el cuento de Borges en un sentido político-nobiliario como hijo de la reina Pasífae, pero también con un sentido ontológico - cada ser es único-) requiere de un «otro» para su conformación, pues los tres reyes se configuran por contraposición con un doble.

\section{CONSIDERACIONES FINALES}

En esta dislocación de la historia originaria, tanto Cortázar como Borges invirtieron el sentido del mito de acuerdo con sus concepciones de la realidad, de acuerdo con sus propias lecturas de este mito. El resultado de la transformación de algunos de los elementos más corrientes del mito son unos nuevos metarrelatos propios de sus tiempos, pues dan lugar a unas obras que potencian precisamente la sensibilidad creadora, la formación de una cultura generadora. Con ello, además, Borges y Cortázar se apropian del mito de Teseo y el Minotauro y aprovechan las funciones sociales y especulativas para acercar el 
mito a una sociedad como la argentina, que no cuenta con el respaldo de una gran civilización antigua y cuyo proceso de culturización se ha destacado por ser predominantemente occidental, europeo.

Los mitos ya no son tanto parte de la cultura oral como sí del acervo literario, de ahí que sean susceptibles de experimentar transformaciones determinadas por los fines estéticos, las técnicas o los géneros literarios a los que recurren, pero también por los intelectuales, emocionales e incluso políticosociales con los que neutralizan ese carácter repetitivo de los mitos heroicos en cuanto a sus temas y los límites racionales con los que se ata la fantasía, según Kirk (1992: 174-175). Así, las particulares relecturas del mito clásico de estos escritores pretenden devolverle a la historia clásica del minotauro su antigua intensidad y, por tanto, «actualizarla» para así mantener su efecto e impacto en las nuevas lecturas, lo que según G. Steiner

equivale a conferirle [al texto original] una dignidad inmediata, y a involucrarlo en una dinámica de magnificación (sujeta por supuesto, a posterior revisión, y, quizá, hasta a destitución) [en la que] el desplazamiento de la transferencia y de la paráfrasis acrece la estatura del original. (Steiner 1980: 344)

En ambas adaptaciones se innova a partir de una marcada reflexividad y un tono nostálgico sobre el mito, incluyendo las propias obsesiones e inquietudes personales, y las nuevas versiones responden a miedos y anhelos de sus autores y se explican a partir de su pensamiento y experiencias vitales. Podemos decir que ambos buscan cambiar el modo de pensar al rehacer el mito, que es, en definitiva, reflejo de una determinada concepción del mundo y de la naturaleza humana. Sin embargo, la importancia de la elección de este mito y su «reelaboración» no ha cesado de radicar en lo que Eliade (1992: 149) ha cifrado en el interés de los hombres por el mito entendido como «algo vivo» en el que «el mundo no es ya una masa opaca de objetos amontonados arbitrariamente, sino un cosmos viviente, articulado y significativo [que] se revela como lenguaje».

\section{BIBLIOGRAFÍA}

AlVARADO, T. (2019), «El Minotauro y su transformación. Un recorrido desde el Siglo de Oro hasta el siglo XX. Desde la alegoría hasta la búsqueda ética», Anagnórisis. Revista de investigación teatral, 20, 34-55.

Alsina Clota, J. (2000), Aristóteles. Poética, Barcelona, Icaria.

BARTHES, R. (1994), El susurro del lenguaje. Más allá de la palabra y de la escritura, Barcelona, Paidós.

BORGES, J. L. (1971), El Aleph, Madrid, Alianza.

BORGES, J. L. (1984), Obras completas 1964-1975, vol. III, Barcelona, Círculo de Lectores.

Borges, J. L. y Guerrero, M. (1966), Manual de zoología fantástica, México, Fondo de Cultura Económica.

CORTÁzAR, J. (1970), Los Reyes, Buenos Aires, Sudamericana.

CORTÁZAR, J. (1980 [2015]), Clases de literatura. Berkeley, 1980, Barcelona, Debolsillo. 
CORTÁZAR, J. (1994 [2017]), Obra crítica, Barcelona, Debolsillo.

Eliade, M. (1992), Mito y realidad, Barcelona, Labor.

Genette, G. (1989), Palimpsestos. La literatura en segundo grado, Madrid, Taurus.

KIRK, G. S. (1992), La naturaleza de los mitos griegos, Barcelona, Labor.

KAPPLER, C. (2004), Monstruos, demonios y maravillas a fines de la Edad Media, Madrid, Akal.

KRISTEVA, J. (1988), El lenguaje, ese desconocido. Introducción a la lingüística, Madrid, Fundamentos.

SANTIESTEBAN, H. (2003), Tratado de monstruos: ontología teratológica, México, Plaza y Valdés.

SCAVINO, L. Y BUZÓN, R. (2008), «Traducción y transtextualidad en 'La casa de Asterión' de J. L. Borges: una poética de la polifonía», Espéculo: Revista de Estudios Literarios, 38. Disponible en: <http://webs.ucm.es/info/especulo/numero38/asterion.html>. 
